\title{
The role of root architectural traits in adaptation of wheat to water-limited environments
}

\author{
Ahmad M. Manschadi ${ }^{\mathrm{A}, \mathrm{D}}$, John Christopher ${ }^{\mathrm{B}}$, Peter deVoil $^{\mathrm{A}}$ and Graeme L. Hammer ${ }^{\mathrm{C}}$

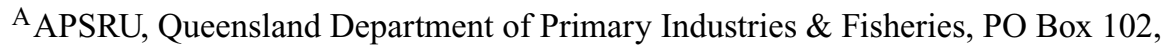 \\ Toowoomba, Qld 4350, Australia. \\ ${ }^{B}$ Queensland Department of Primary Industries \& Fisheries, Leslie Research Centre, \\ PO Box 2282, Toowoomba, Qld 4350, Australia. \\ ${ }^{C}$ APSRU, School of Land and Food Sciences, The University of Queensland, Brisbane, Qld 4072, Australia. \\ ${ }^{\mathrm{D}}$ Corresponding author. Email: ahmad.manschadi@dpi.qld.gov.au
}

\begin{abstract}
Better understanding of root system structure and function is critical to crop improvement in waterlimited environments. The aims of this study were to examine root system characteristics of two wheat genotypes contrasting in tolerance to water limitation and to assess the functional implications on adaptation to water-limited environments of any differences found. The drought tolerant barley variety, Mackay, was also included to allow inter-species comparison. Single plants were grown in large, soil-filled root-observation chambers. Root growth was monitored by digital imaging and water extraction was measured. Root architecture differed markedly among the genotypes. The drought-tolerant wheat (cv. SeriM82) had a compact root system, while roots of barley cv. Mackay occupied the largest soil volume. Relative to the standard wheat variety (Hartog), SeriM82 had a more uniform rooting pattern and greater root length at depth. Despite the more compact root architecture of SeriM82, total water extracted did not differ between wheat genotypes. To quantify the value of these adaptive traits, a simulation analysis was conducted with the cropping system model APSIM, for a wide range of environments in southern Queensland, Australia. The analysis indicated a mean relative yield benefit of $14.5 \%$ in water-deficit seasons. Each additional millimetre of water extracted during grain filling generated an extra $55 \mathrm{~kg} \mathrm{ha}^{-1}$ of grain yield. The functional implications of root traits on temporal patterns and total amount of water capture, and their importance in crop adaptation to specific water-limited environments, are discussed.
\end{abstract}

Keywords: APSIM, barley, drought, root characteristics, simulation modelling, water uptake.

\section{Introduction}

Water limitation during the life cycle of crops is a crucial factor affecting crop yield in rain-fed agricultural systems worldwide. Crop yield losses vary according to timing and severity of water limitation. The 2002-2003 drought in Australia, for instance, resulted in an estimated $30 \%$ reduction in agricultural output (Horridge et al. 2005). Increasing crop yields in water-limited environments requires genotypes with improved tolerance to water limitation combined with management practices that aim to maximise water availability (Fischer 1996; Angus and van Herwaarden 2001; Passioura 2006). Yield improvement from traditional plant breeding based on selection for yield per se, however, has been slow. This is primarily due to large genotype $\times$ environment $(G \times E)$ interactions for yield, which result from a combination of differences in genotypic adaptation and seasonal variation in quantity and distribution of rainfall (Cooper et al. 2001; Richards et al. 2002). Integrating physiological understanding with traditional breeding has been proposed as a means to enhance the rate of yield improvement (Jackson et al. 1996; Hammer et al. 2005). In this approach, traits conferring tolerance to water limitation are dissected, and secondary physiological traits associated with improved yield are identified. While several shoot-related physiological traits have been identified and used as secondary selection criteria in breeding programs (Fischer et al. 1989; Fukai et al. 1999; Reynolds et al. 2000; Araus et al. 2002; Richards et al. 2002), root-related droughtadaptive characteristics have been neglected because of limited knowledge of root system growth and functioning,

Abbreviations used: $\mathrm{G} \times \mathrm{E}$, genotype $\times$ environment; PAWC, plant available water content; RM, root modified. 
difficulties in measuring root traits, and lack of simple and efficient root screening methods. Genotypic variation for root characteristics and their functional implications for water uptake and increased yields under water-deficit conditions have been reported for many crop species (O'Toole and Bland 1987). In wheat (Triticum aestivum L.), the desirable traits include the depth of rooting (Hurd 1974), root elongation rate (O'Brien 1979), root distribution at depth (Hurd 1968; O'Brien 1979; Manske and Vlek 2002), xylem vessel diameter (Richards and Passioura 1989), angle of seminal roots (Nakamoto and Oyanagi 1994), and root: shoot dry matter ratio (Siddique et al. 1990).

The usefulness of individual root traits in increasing grain yield under water-limited conditions is largely determined by the pattern of water stress development in the target production environments. For instance, in environments where crops are grown largely on stored soil moisture with a substantial risk that water may run out before the completion of grain filling, such as in the north-eastern Australian wheatbelt, reducing the pre-anthesis water use by decreasing the diameter of xylem vessels (i.e. increasing the hydraulic resistance) results in improved post-anthesis water availability and, hence, greater grain yield (Passioura 1972). Richards and Passioura (1989) used this root trait in a breeding program to successfully develop wheat genotypes with improved yields in drier environments. Further, greater depth of rooting and high root-length density at depth also appear beneficial in those environments as they increase the water-capturing capacity of the root system particularly during the grain filling period (Passioura 1983; Ludlow and Muchow 1990). In contrast, in the Mediterranean environments where crops rely largely on seasonal rainfall, higher root dry matter, root-length density, and root surface area early in the season are critical for increased early vigour and pre-anthesis water use, and hence improved water-use efficiency and grain yield of wheat crops (Rebetzke and Richards 1999; Liao et al. 2004).

Simulation modelling provides a valuable framework to quantify and predict plant responses to genetic, environmental, and management factors. By capturing the current scientific understanding of physiological determinants of crop growth and development, mechanistic crop models offer a great potential to integrate physiological understanding with plant breeding to (i) quantitatively assess the impact of specific traits on crop yield, (ii) design ideotypes for target environments, and (iii) examine the causes of $\mathrm{G} \times \mathrm{E}$ interaction for quantitative traits such as grain yield (Shorter et al. 1991; Hammer et al. 1996, 2002). Systems analysis of putative plant traits, using mechanistic crop models to predict crop responses under water-limited conditions, has largely focused on shoot-related characters such as phenology, transpiration efficiency, osmotic adjustment, leaf size and appearance rate, grain growth rate and duration (Muchow and Carberry 1993; Hammer et al. 1996;
Sinclair and Muchow 2001; Chapman et al. 2002; Sinclair et al. 2005). In only a few simulation studies has the impact of modified root traits on water uptake and crop yield been quantified. Sinclair and Muchow (2001) demonstrated that simulated maize yields were enhanced by an increased depth of rooting in all test environments. Similar results were reported from a simulation analysis of wheat in low-rainfall areas of South Australia (Dreccer et al. 2002). Further, Dreccer et al. (2002) reported that limiting water uptake from deeper soil layers early in the season, i.e. greater root-length distribution in the surface horizons, resulted in increased availability of water for post-anthesis growth and, hence, improved wheat grain yields.

The objectives of this study were (i) to experimentally examine root system characteristics and water extraction patterns of a wheat line tolerant to water limitation, SeriM82, a standard wheat cultivar, Hartog, and a drought-tolerant barley (Hordeum vulgare L.) cultivar, Mackay [SeriM82 is a high-yielding CIMMYT line that has been shown to yield on average $12 \%$ more than Hartog in multi-environment trials (METs) in north-eastern Australia (Peake et al. 1996; Cooper et al. 1999)], and (ii) to explore via systems analysis of the root traits observed for SeriM82, the likely impacts of root system modifications on capacity to capture water and affect grain yield. The cropping system model APSIM (Keating et al. 2003) was adapted for the simulation analysis of a hypothetical wheat genotype with SeriM82-like rooting patterns across a wide range of rainfed environments in southern Queensland, Australia.

\section{Materials and methods}

\section{Root chamber experiment}

Root growth and water extraction patterns of two wheat genotypes, Hartog and SeriM82, and the barley cultivar, Mackay, were studied in large root-observation chambers. The root chamber experiment was conducted in the winter growing season 2004 at the Queensland Department of Primary Industries and Fisheries, Toowoomba $\left(27^{\circ} 31^{\prime} 58^{\prime \prime} \mathrm{S}, 151^{\circ} 56^{\prime} 8^{\prime \prime} \mathrm{E}\right)$, Australia. The root chambers ( $240 \mathrm{~cm}$ wide, $120 \mathrm{~cm}$ deep and $10 \mathrm{~cm}$ thick) were constructed using steel frames with Perspex sides $(0.8 \mathrm{~cm}$ thick) (Broad and Hammer 2004), and filled with a soil mixture consisting of brown vertisol, composted cattle manure, and coarse sand $(50: 30: 20 \mathrm{vol} \%)$. To ensure non-limiting supply of nutrients, pellets of Osmocote ${ }^{\circledR}$ slow-release fertiliser were added to the soil mixture. Prior to planting, the soil was saturated and then allowed to drain for several days. Three seeds of each genotype were placed in each root chamber at a depth of $5 \mathrm{~cm}$ on 11 June. Seedlings were thinned to one per chamber following emergence and water was added again until drainage was observed from the bottom of the chambers. To minimise evaporative losses, the soil surface was covered with a 5-cm layer of fine mulch. No more water was added during the plant growth period. Light was excluded from the Perspex sides of the chambers with vinyl covers except during root observations. The root chambers were arranged in a complete randomised block design with three replicates per genotype in a poly-house.

Root growth at the Perspex surface was monitored at 2-3-week intervals by taking digital images of roots with a digital camera ( 5 mega pixels) attached to a portable steel frame and mounted in front of the chamber. While taking images, the frame was covered with a screen 
excluding $95 \%$ of sunlight. A total of 40 images $(30 \times 22.5 \mathrm{~cm})$ were required to cover the whole surface of each Plexiglas plate. Each image was cropped to two segments $(15 \times 22.5 \mathrm{~cm})$ and the total root length per segment was determined using the WinRHIZO Tron MF software (Regent Instruments Inc., Quebec, Canada).

At crop maturity, plants were harvested and dissected into leaves, stems, heads, and grains. The number and dry weight (oven-drying at $65^{\circ} \mathrm{C}$ for $72 \mathrm{~h}$ ) of plant organs were determined for each plant. The chambers were then laid on one side and the upper Perspex was removed for gravimetric soil water sampling. Soil samples were taken from the centre of each $30 \times 22.5 \mathrm{~cm}$ section with a cylindrical cutter $(7.5 \mathrm{~cm}$ long, $10 \mathrm{~cm}$ diameter). Soil samples from an unplanted chamber were used to determine the soil bulk density and water content at drained upper limit. Air temperature in the poly-house and soil temperature at 20 and $90 \mathrm{~cm}$ depths in two root chambers were monitored with a portable solar-powered weather station (Campbell Scientific Australia Pty Ltd., Hyde Park, Qld).

Analysis of variance was carried out by the GLM (General Linear Model) procedure of the SAS statistical package (SAS Institute Inc. 1991). Significant differences in the mean values were determined by the Tukey-Test (Tukey's Honest Significant Difference) at a significance level of 0.05 . Regression analysis was conducted with SigmaPlot (version 9.0, Systat Software Inc.).

\section{Model description and simulation analysis}

The cropping systems model APSIM (Keating et al. 2003, http://www.apsim.info/apsim/; verified 14 June 2006) was used to examine the likely effects of modified root traits on wheat growth and yield formation across a wide rage of environments in southern Queensland (QLD), Australia. The key APSIM modules deployed in this analysis were WHEAT (wheat crop growth and development), SOILWAT (soil water balance), SOILN (soil nitrogen dynamics), RESIDUE (surface residue dynamics), and MANAGER (specifying management rules)

The APSIM-WHEAT module is based on a generic plant template (Robertson et al. 2002; Wang et al. 2002) and simulates wheat phenology, biomass production and partitioning, yield formation, root growth, and water uptake in response to genetic, environmental and management factors using a daily time-step. The model uses a simple framework to account for the effects of root growth on the amount and timing of soil water uptake (Passioura 1983; Monteith 1986). In this approach, rooting depth, calculated via a crop-specific potential root elongation rate $\left(\mathrm{mm} \mathrm{day}^{-1}\right)$, determines the depth of soil water extraction. The potential rate of water extraction in the rooted soil layers is calculated using a layer-specific empirical constant $(\mathrm{kl})$, which describes the fraction of available soil water that can potentially be taken up per day. The parameter $k l$ integrates the effect of root length density $\left(l, \mathrm{~cm}_{\text {root } \mathrm{cm}^{-3}}\right.$ soil) and soil diffusivity $\left(k, \mathrm{~cm}^{-2}\right.$ day $)$, and must be defined for each combination of crop and soil type. Values of $k l$ typically vary between 0.01 for deep layers with low root-length densities to 0.10 for densely rooted surface layers. The adequacy and robustness of this framework for modelling soil water supply has been demonstrated for wheat (Meinke et al. 1997) as well as for a range of other crops and crop cultivars grown under different soil conditions (Meinke et al. 1993;
Robertson et al. 1993; Dardanelli et al. 1997). Following the estimation of the potential water supply, the actual rate of water extraction in the model is determined as the lesser of the sum of the potential water extraction rates from all rooted layers and the crop transpiration demand. Under supply-limited conditions, the ratio of water supply to demand is used to derive water deficit factors that affect crop phenology, biomass production, and leaf area expansion. The APSIM modules used in this study have been parameterised and extensively tested for simulating the growth and yield of wheat cultivar Hartog across environments with differing water availability in north-eastern Australia (Asseng et al. 1998a; Meinke et al. 1998; Keating et al. 2001; Wang et al. 2003).

For the systems analysis of root traits, APSIM simulations were run with 105 years of daily weather data from three locations in southern Queensland (QLD), Australia (Table 1). The weather data were extracted from the SILO website (www.nrm.qld.gov.au/silo/; verified 14 June 2006). The sites differed substantially in the soil type and the maximum amount of plant available water content (PAWC) in the profile. Roma represented a low-yielding, Oakey a high-yielding, and Goondiwindi an intermediate-yielding wheat environment, respectively. In each year of simulation, Hartog was sown on 1 June at a density of 100 plants $\mathrm{m}^{-2}$ under non-limiting nitrogen supply. To generate a wide range of standard starting soil water conditions, the soil profile at sowing was assumed to be recharged to one-third, two-thirds and full level of PAWC, each year at each site. In the second set of simulations, instead of Hartog, a root-modified (RM) wheat genotype was sown. The RM genotype represented a hypothetical wheat line with the above-ground characteristics of Hartog but root attributes of the drought-tolerant genotype SeriM82 as identified in the root chamber experiment. The changes made in the APSIM parameters to account for the altered root traits are presented below.

\section{Results}

\section{Root chamber experiment}

\section{Weather conditions in the poly-house}

The mean daily air temperature during the winter growing season in the poly-house ranged from 7.8 to $25.8^{\circ} \mathrm{C}$. The soil temperatures in the root chambers at 20 and $90 \mathrm{~cm}$ depths followed air temperature closely (Fig. 1). There was a slight gradient in soil temperature within the root chamber with temperatures at $20 \mathrm{~cm}$ being on average $0.8^{\circ} \mathrm{C}$ higher than those measured at $90 \mathrm{~cm}$ soil depth. The solarweave cover of the poly-house allowed transmission of $75 \%$ of incident photosynthetically active radiation.

\section{Rooting depth and lateral root spread}

The visible depth of rooting did not differ between wheat and barley genotypes. At anthesis, all genotypes had reached a depth of $95 \mathrm{~cm}$. Root growth continued during the reproductive phase and at around mid-grain-filling roots

Table 1. Characteristics of sites and soil types used in the wheat simulation analysis

PAWC is the maximum plant available water content in the soil profile

\begin{tabular}{|c|c|c|c|c|c|}
\hline$\overline{\text { Site }}$ & Latitude/longitude & Mean annual rainfall $(\mathrm{mm})$ & Soil type & Soil depth $(\mathrm{mm})$ & $\overline{\text { PAWC }(\mathrm{mm})}$ \\
\hline Roma & $26.54 \mathrm{~S} / 148.78 \mathrm{E}$ & 590 & Brown Vertisol & 800 & 130 \\
\hline Goondiwindi & $28.55 \mathrm{~S} / 150.31 \mathrm{E}$ & 620 & Red Chromosol & 1400 & 185 \\
\hline Oakey & $27.40 \mathrm{~S} / 151.74 \mathrm{E}$ & 645 & Black Vertisol & 1900 & 300 \\
\hline
\end{tabular}




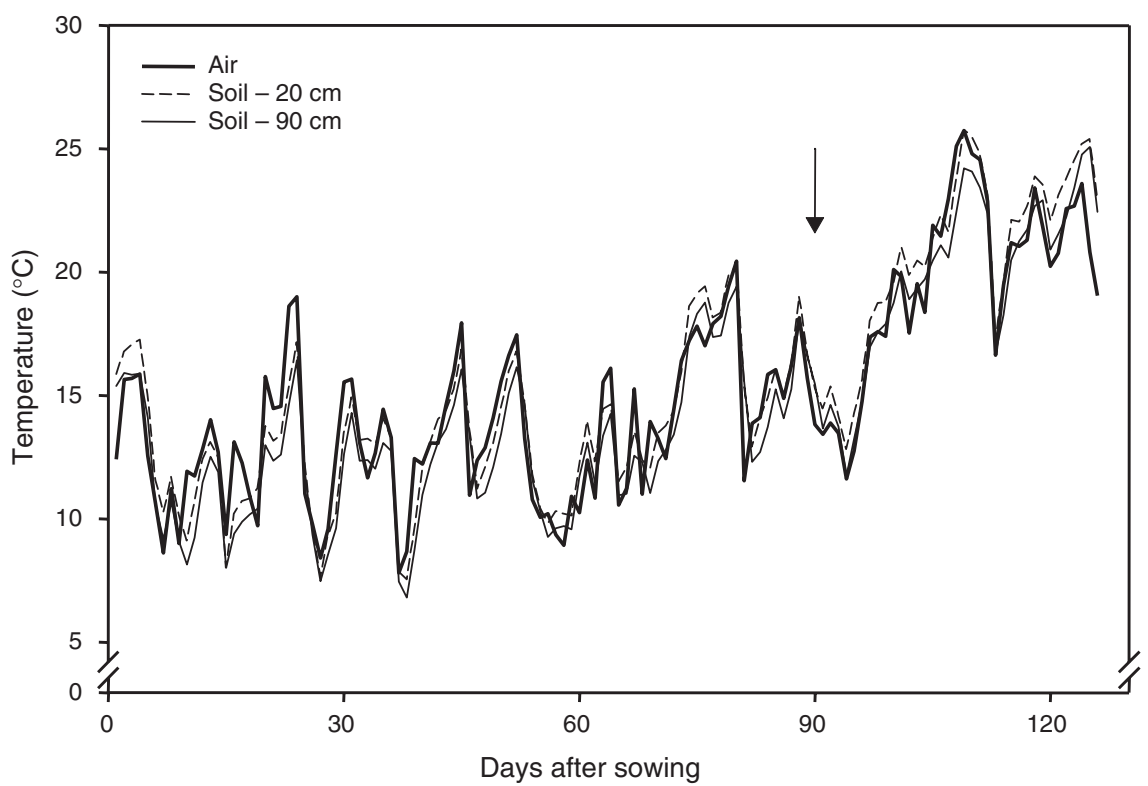

Fig. 1. Daily mean air temperature and soil temperatures at 20 and $90 \mathrm{~cm}$ depths in the root chambers during the wheat growth cycle in the poly-house. The arrow indicates the commencement of anthesis in wheat.

arrived at the bottom of the root chamber (depth $112.5 \mathrm{~cm}$ ). The lateral root spread, however, varied markedly among the genotypes. The drought-tolerant wheat line SeriM82 exhibited the most compact root system with a maximum lateral spread of only $45 \mathrm{~cm}$ from the stem base. The horizontal spread of the root system in the standard wheat cultivar Hartog was $28 \%$ more than that of SeriM82 (Fig. 2). Barley cv. Mackay explored the largest soil volume with a maximum lateral root spread of $\sim 75 \mathrm{~cm}$ from the plant base.

\section{Patterns of root length distribution}

The mean total root length visible on the transparent panels for SeriM82 $(66.9 \pm 5.2 \mathrm{~m})$ and Hartog $(73.7 \pm 4.5 \mathrm{~m})$ did not differ significantly at anthesis. However, the wheat genotypes differed substantially in the pattern of root distribution with depth (Fig. 3). Whereas the measured root lengths in the central sections of the upper three soil layers (sections 16-18 and 21-23) were similar in both wheat genotypes, there were significant differences in root growth in the lateral sections

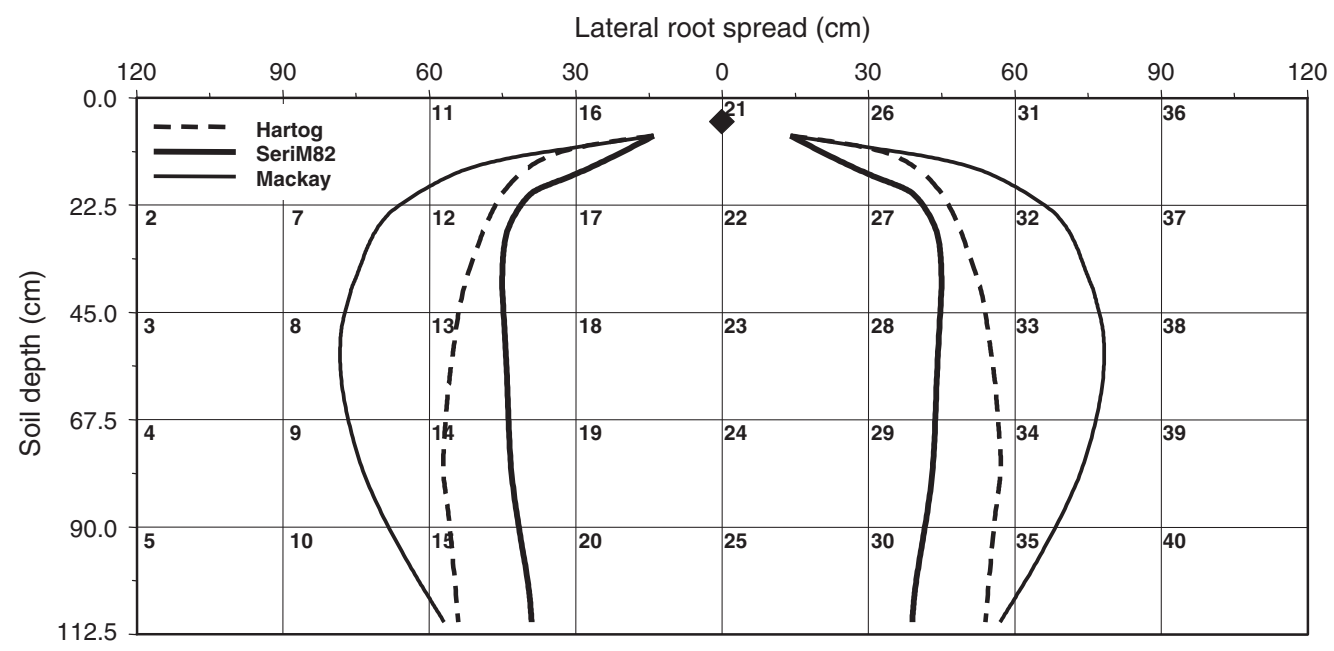

Fig. 2. Spatial root system configuration of the drought-tolerant wheat line SeriM82, the standard wheat cultivar Hartog, and the barley variety Mackay grown in root observation chambers at crop maturity. Numbered squares with solid lines indicate the $30 \times 22.5 \mathrm{~cm}$ sections of the transparent sides used for root digital imaging. Symbol (diamond) represents the plant base. 


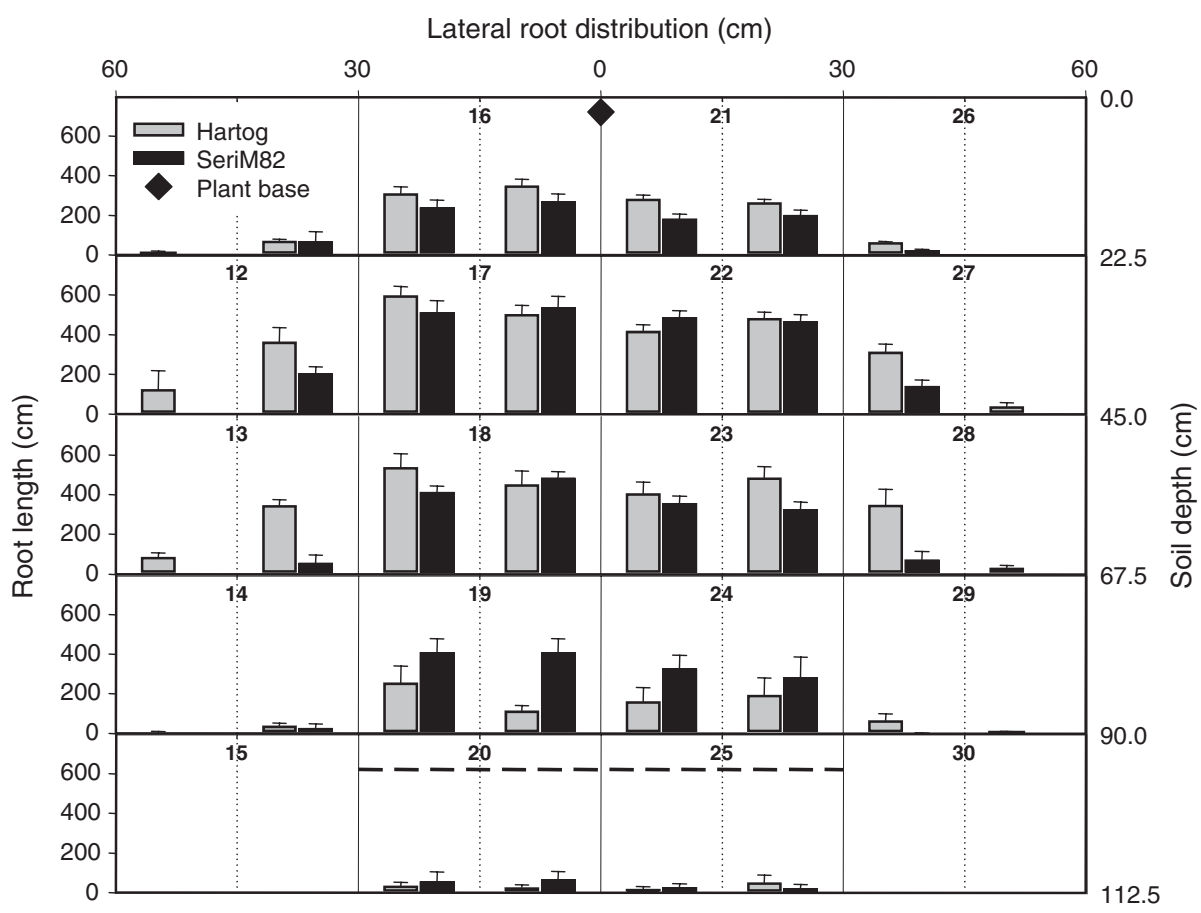

Fig. 3. Spatial pattern of root length distribution in the drought-tolerant wheat genotype SeriM82 compared with the standard wheat variety Hartog observed at the transparent surface of the root chambers at crop anthesis. The bars indicate standard error of mean and the dashed line represents the visible root depth for both genotypes (section numbering is as for Fig. 2).

(11-13 and 26-28) and in the fourth soil layer (sections 19 and 24). Compared with Hartog, the drought-tolerant line SeriM82 allocated less root growth laterally and produced more root length at depth.

Root growth in both genotypes continued until late in the grain filling phase (Fig. 4). The post-anthesis root length increase represented a greater proportion of total root growth for SeriM82 (33.2\%) than for Hartog (14.2\%). During the post-anthesis phase, new root growth was observed in all sections except the topsoil layer and the central sections 17, 18, 22, and 23 (Fig. 4). While the root system of Hartog extended in both horizontal and vertical directions, SeriM82 allocated proportionally more root growth to the central sections in the deepest soil layer. Consequently, the average total root length of SeriM82 in the deepest soil layer $(90-112.5 \mathrm{~cm})$ was 3.8 times greater than that of Hartog.

In addition to differences in spatial root distribution, visible evaluation of root images indicated that the roots of SeriM82 occupied the available soil volume in each section more uniformly, while Hartog tended to exhibit a less even root distribution. This was evident in those sections where the total root length was similar for both genotypes. Figure 5 illustrates, as an example, the differences between Hartog and SeriM82 in the uniformity of root distribution as traced on the digital images taken from the section 23 of the root chambers at crop maturity. Further, it shows the significant genotypic variation in root length observed in the deepest soil layer as illustrated for section 25 of the root chambers at crop maturity. The root lengths of Mackay measured in each section were generally similar to those of Hartog (data not shown).

\section{Water extraction and biomass production}

To examine genotypic differences in the spatial pattern of soil water extraction, only the soil cores taken from the fully rooted central sections (17-20 and 22-25) were considered because the lateral sections representing the outer edges of the root system in SeriM82 (11-15 and 26-30) were not completely explored by the roots. Across the central sections, SeriM82 appeared to be the most effective genotype in terms of water uptake per unit soil volume (Fig. 6). Compared with Hartog, SeriM82 extracted on average $10.9 \%$ more water from the shallower sections $(17,22,18$, and 23$)$ and $24.7 \%$ more water from the deeper sections $(19,24,20$, and 25). Water uptake by the barley cv. Mackay was similar to that of Hartog. The total water use, above-ground dry matter at crop maturity, and biomass partitioning into various plant organs did not differ significantly between the wheat genotypes (Table 2). Barley cv. Mackay extracted significantly more water and produced a greater amount of biomass than the wheat genotypes. The grain yield, however, was similar for all three genotypes. 


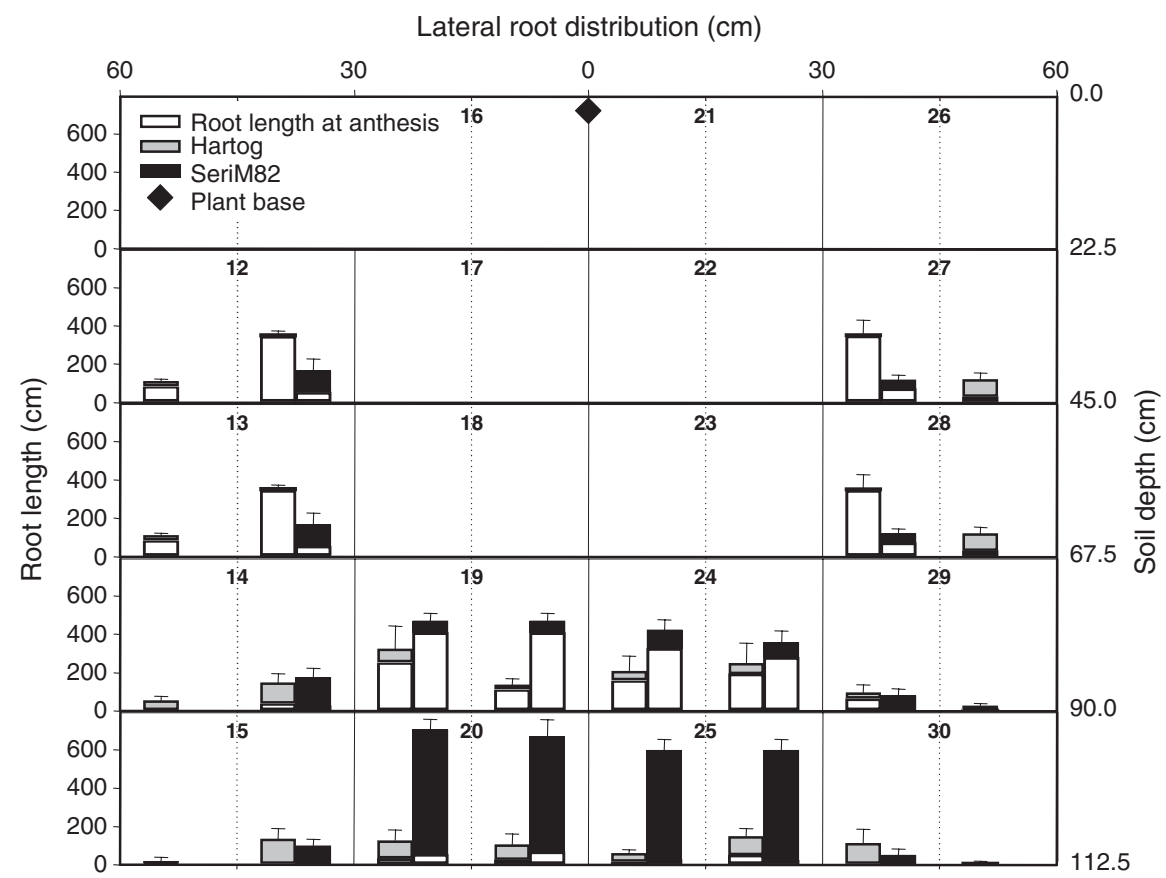

Fig. 4. Post-anthesis increase in root length in the drought-tolerant wheat genotype SeriM82 compared with the standard wheat variety Hartog measured at the transparent surface of the root chambers. The bars indicate standard error of the mean. Sections with no bars did not exhibit net root growth in the period from anthesis to maturity (section numbering is as for Fig. 2).
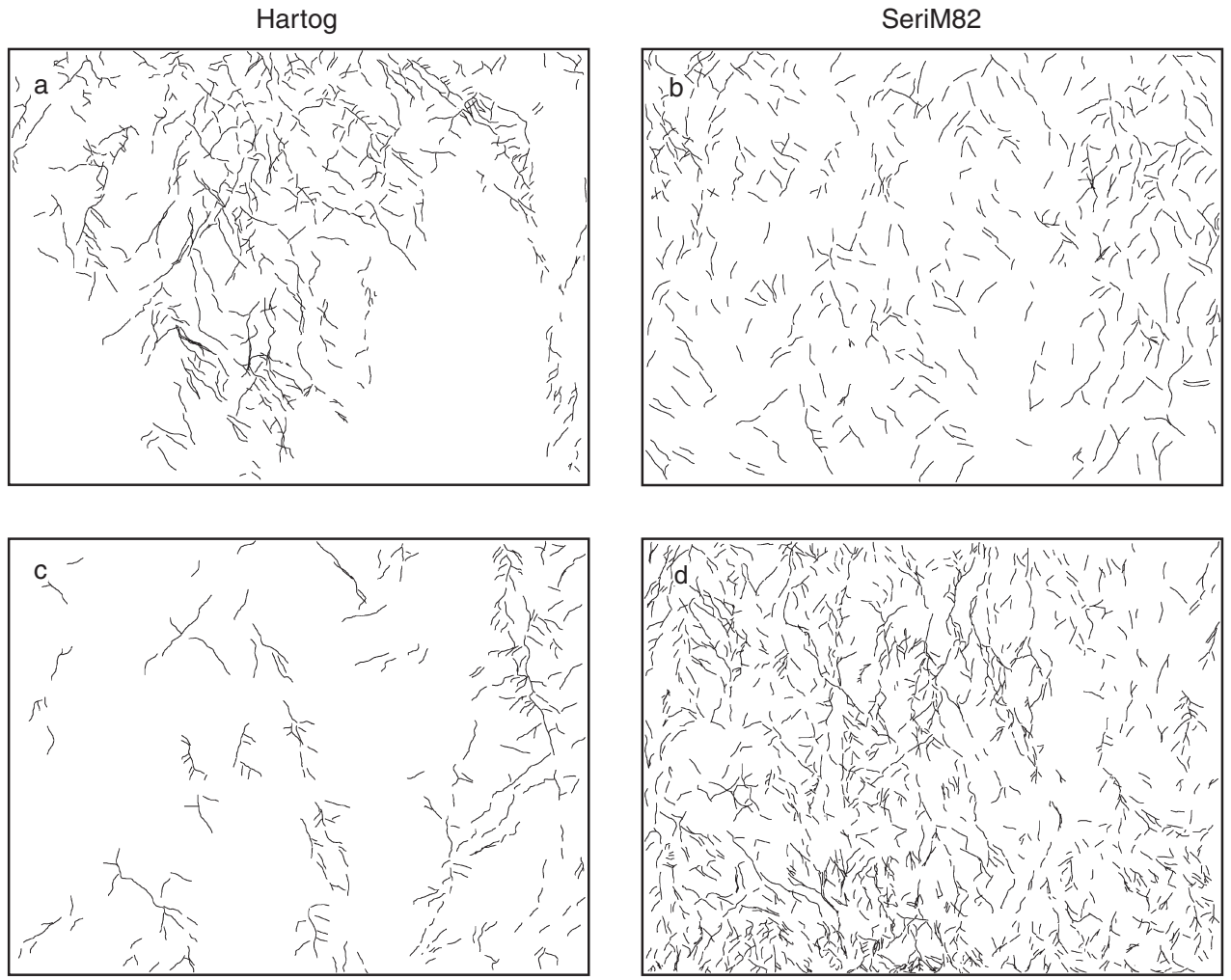

Fig. 5. Differences in the distribution of roots $(a, b)$ and root length production $(c, d)$ between the standard wheat cultivar Hartog and the drought-tolerant line SeriM82 illustrated by tracing the roots on the digital images taken from the section $23(a, b)$ and $25(c, d)$ of the root chambers at crop maturity. 


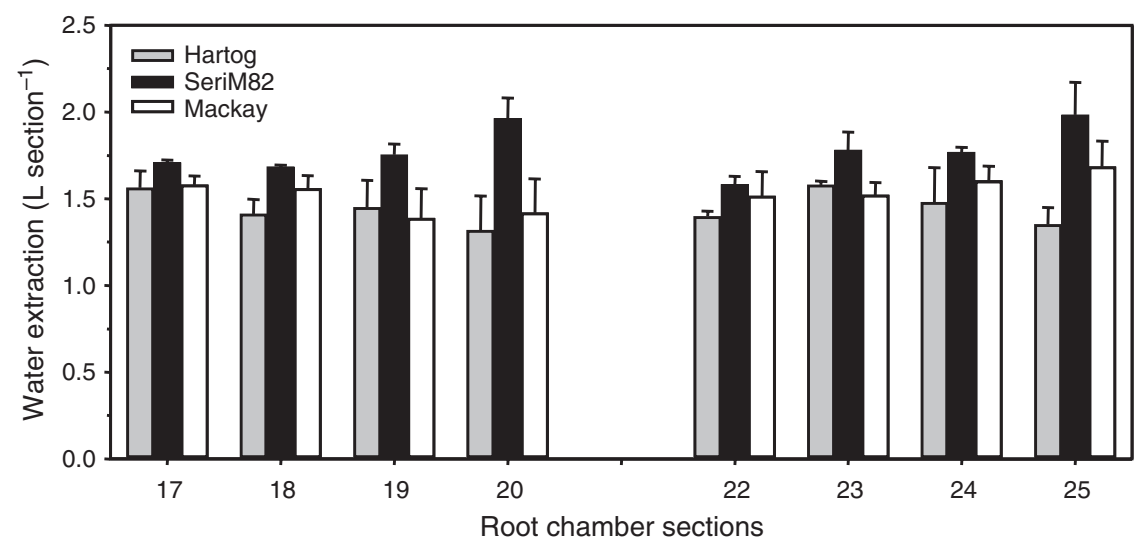

Fig. 6. Soil water uptake from each of the central sections of the root chambers in the droughttolerant wheat line SeriM82, standard wheat cultivar Hartog, and the barley cultivar Mackay measured at crop maturity. The bars indicate standard error of the mean.

Table 2. Total above-ground dry matter, dry weights of plant organs, and total water use of wheat (Hartog, SeriM82) and barley (Mackay) genotypes grown in root-observation chambers Values in the parentheses represent standard error of means

\begin{tabular}{lcccccc}
\hline Genotype & $\begin{array}{c}\text { Above-ground } \\
\left(\mathrm{g} \mathrm{plant}^{-1}\right)\end{array}$ & $\begin{array}{c}\text { Leaf } \\
\left(\mathrm{g} \mathrm{plant}^{-1}\right)\end{array}$ & $\begin{array}{c}\text { Stem } \\
\left(\mathrm{g} \mathrm{plant}^{-1}\right)\end{array}$ & $\begin{array}{c}\text { Grain } \\
\left(\mathrm{g} \mathrm{plant}^{-1}\right)\end{array}$ & $\begin{array}{c}\text { Chaff } \\
\left(\mathrm{g} \mathrm{plant}^{-1}\right)\end{array}$ & $\begin{array}{c}\text { Water use } \\
\left(\mathrm{L} \mathrm{plant}^{-1}\right)\end{array}$ \\
\hline Hartog & $123.5(4.23)$ & $10.8(0.97)$ & $32.6(3.99)$ & $56.7(1.43)$ & $23.4(2.90)$ & $25.6(1.97)$ \\
SeriM82 & $119.5(2.39)$ & $12.1(0.18)$ & $31.8(1.99)$ & $52.4(1.65)$ & $23.2(0.16)$ & $24.9(1.86)$ \\
Mackay & $152.5(11.64)$ & $24.7(2.29)$ & $52.7(4.71)$ & $58.9(5.02)$ & $16.2(1.50)$ & $32.4(2.05)$ \\
\hline
\end{tabular}

\section{Simulation analysis}

Model adaptation to simulate the root-modified genotype

To represent the RM genotype, APSIM parameters were altered to account for the two root system characteristics likely to be responsible for the better yields of SeriM82; i.e. greater root length formation in the soil layers below $70 \mathrm{~cm}$ and more uniform rootbranching pattern. To account for the effects of these root traits on water uptake in APSIM, we assumed that greater root-length density in a soil layer is associated with increased rate of water extraction, i.e. improved 'effectiveness' of roots, while more even root-branching structure results in a better 'occupancy' of the soil and hence greater amount of water extraction. To simulate improved 'effectiveness', we modified the $k l$ values so that the rate of soil moisture extraction for the RM genotype was the same throughout the soil profile. The $k l$ values used for the standard wheat cv. Hartog decreased with depth representing the common pattern of decreasing root distribution with depth (Fig. 7a). Improved soil 'occupancy' was modelled by altering the crop lower limit of water uptake (LL15) to allow $10 \%$ more water extraction from soil layers below $50 \mathrm{~cm}$ (Fig. 7b).

\section{Simulated effects of modified root traits on wheat yield}

The variation in soil moisture availability among years and sites resulted in simulated grain yields for the standard wheat $\mathrm{cv}$. Hartog ranging from 120 to $8300 \mathrm{~kg} \mathrm{ha}^{-1}$ (Fig. 8). The lowest yield was simulated in the 1940 season at Roma when the stored soil water at sowing was one-third of PAWC and plants received only $18 \mathrm{~mm}$ of rain during the season. A full soil profile at sowing together with $195 \mathrm{~mm}$ of in-crop rain in the 1976 season at Oakey resulted in the maximum predicted yield. The median yields ranged from less than $1000 \mathrm{~kg} \mathrm{ha}^{-1}$ at Roma to more than $6000 \mathrm{~kg} \mathrm{ha}^{-1}$ at Oakey.

Compared with the standard wheat cv. Hartog, root trait modification in the RM genotype and the consequent increase in the potential water uptake, resulted in a mean yield benefit of $\sim 220 \mathrm{~kg} \mathrm{ha}^{-1}$ across all simulated environments. At yield levels below $2000 \mathrm{~kg} \mathrm{ha}^{-1}$, root trait alteration led to improved yields at all three locations (Fig. 9). Only in a very few environments (some seasons at Roma and Goondiwindi) were the simulated yields of the RM genotype less than those of the standard cultivar. The greatest absolute yield differences occurred in the high-yielding environments at Oakey when the initial soil water was assumed to be at full PAWC level. These favourable conditions resulted in a mean simulated yield benefit of $414 \mathrm{~kg} \mathrm{ha}^{-1}$. The 


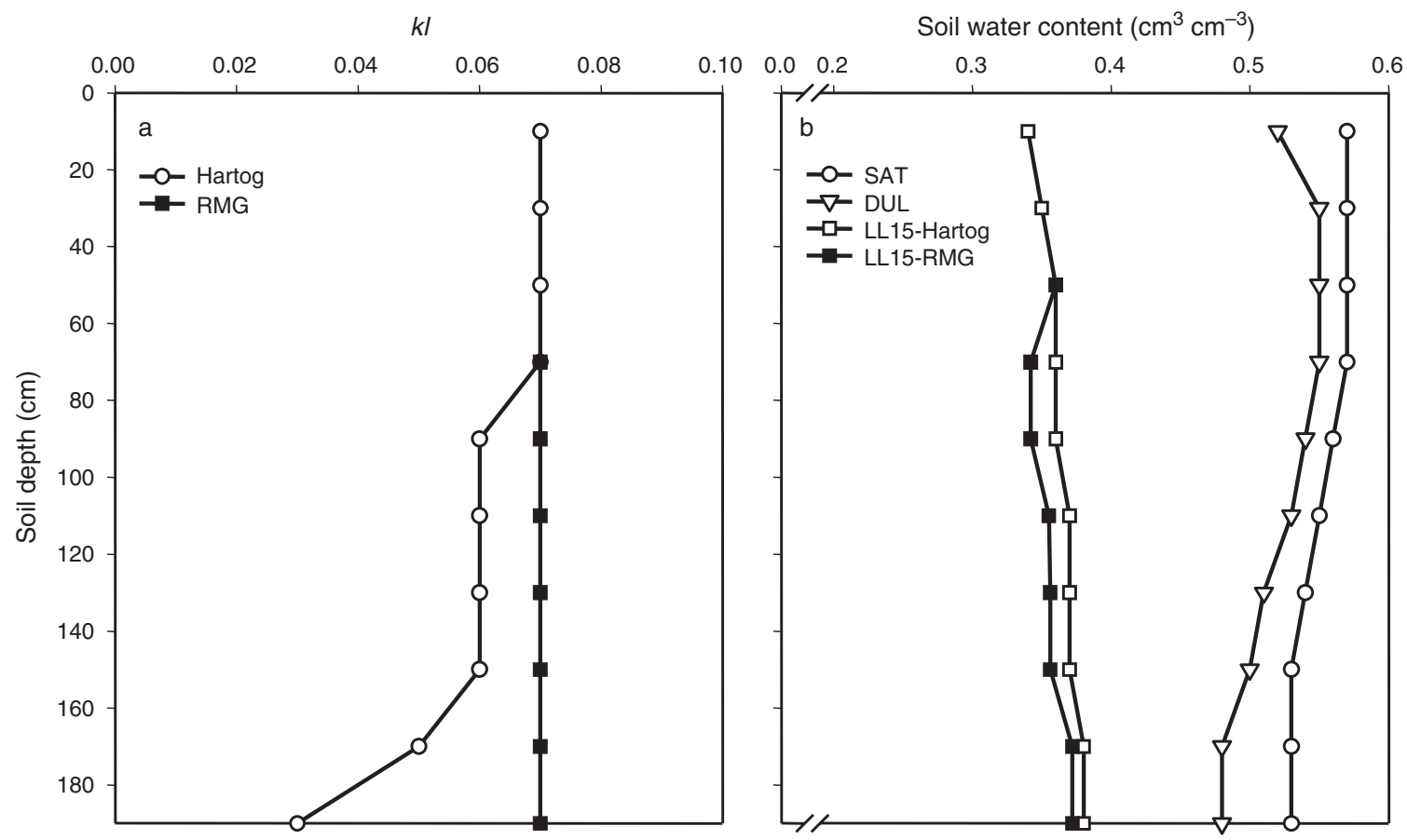

Fig. 7. The rate of water extraction $(k l ; a)$ and crop lower limit of water uptake (LL15; $b$ ) in individual soil layers used in the APSIM simulation analysis for the standard wheat cultivar Hartog and the root-modified genotype (RMG). DUL and SAT indicate drained upper limit and saturated volumetric soil water contents, respectively.

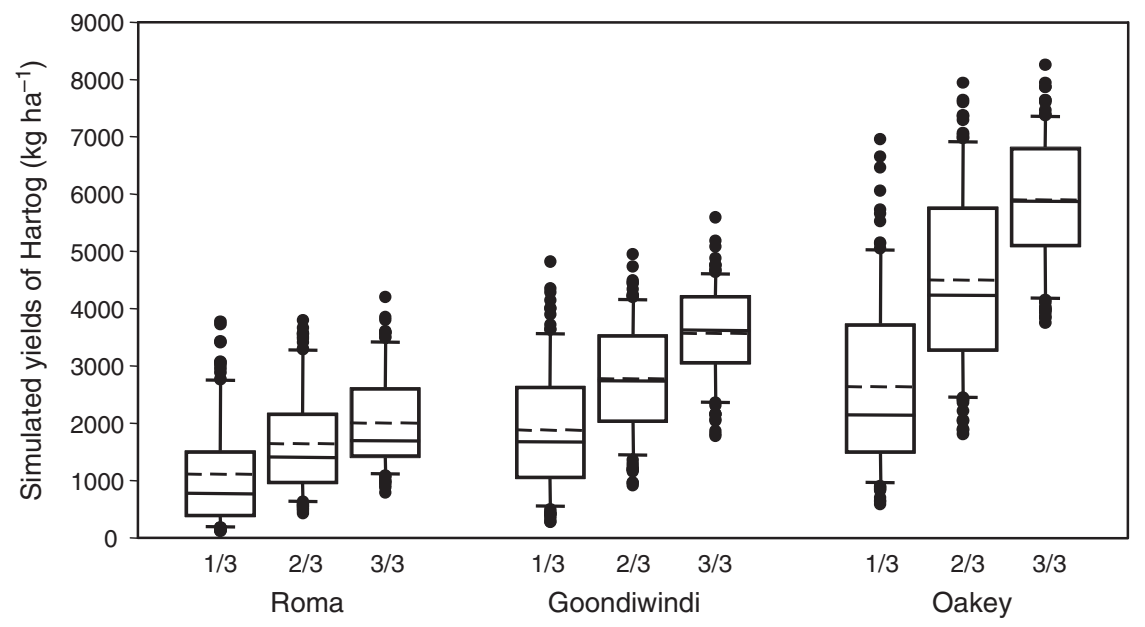

Fig. 8. Simulated yield distributions of the standard wheat cultivar Hartog at Roma, Goondiwindi, and Oakey in southern Queensland, Australia for 1/3, 2/3, and 3/3 fraction of total plant available soil water in the profile at sowing. Boxes represent the 25 th and 75 th percentiles, solid and dashed lines show the median and mean yields, respectively, whiskers mark 10th and 90th percentiles, and symbols indicate the outliers.

relative advantage of the RM genotype over the standard cultivar Hartog, however, was greatest in the water-deficit environments. While the mean relative yield benefit in the simulations starting with one-third of the PAWC was $14.5 \%$, the corresponding figures for the two-thirds and full PAWC levels were only 6.1 and $5.0 \%$, respectively.
The simulated yield differences were closely related to the differences in water uptake capability of genotypes during the grain-filling phase (Fig. 10). The root traits modified in this study resulted in improved access to water during the crop reproductive phase and consequently increased yields in the large majority of simulated environments. The RM genotype 

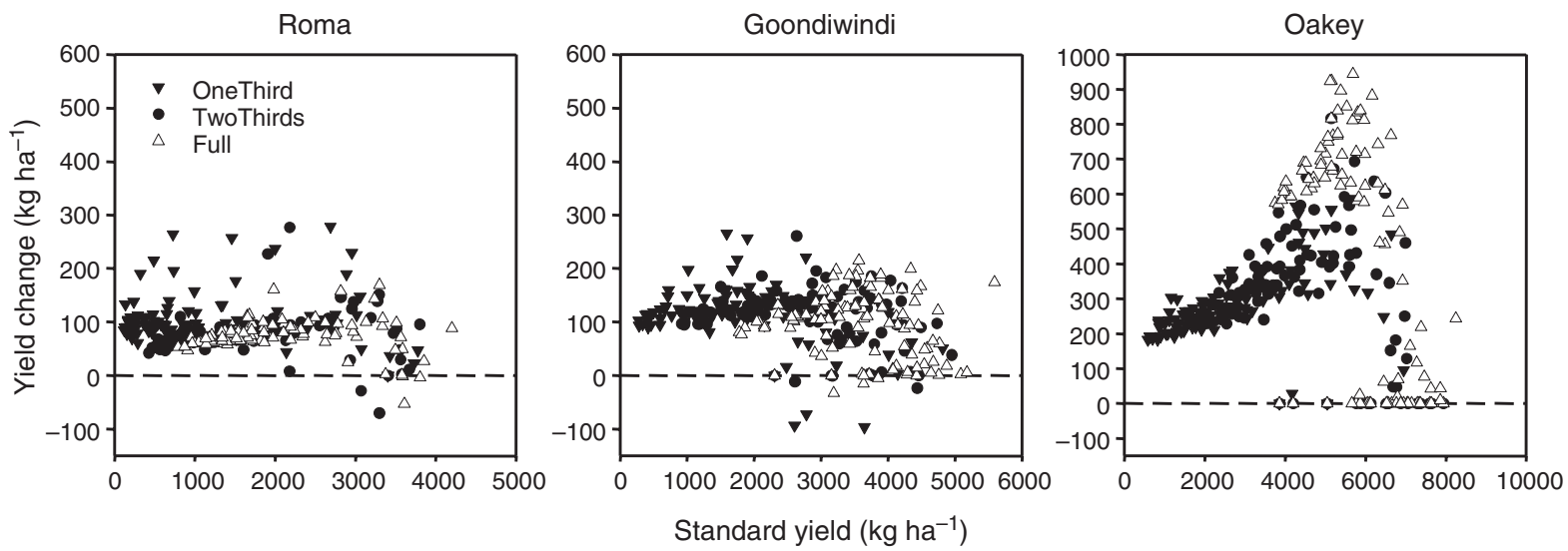

Fig. 9. Yield difference between the standard wheat cultivar Hartog and the RM genotype plotted against yield simulated for Hartog at Roma, Goondiwindi, and Oakey in southern Queensland, Australia. OneThird, TwoThirds, and Full indicate the initial soil water content at sowing as the fraction of total plant available soil water in the profile.

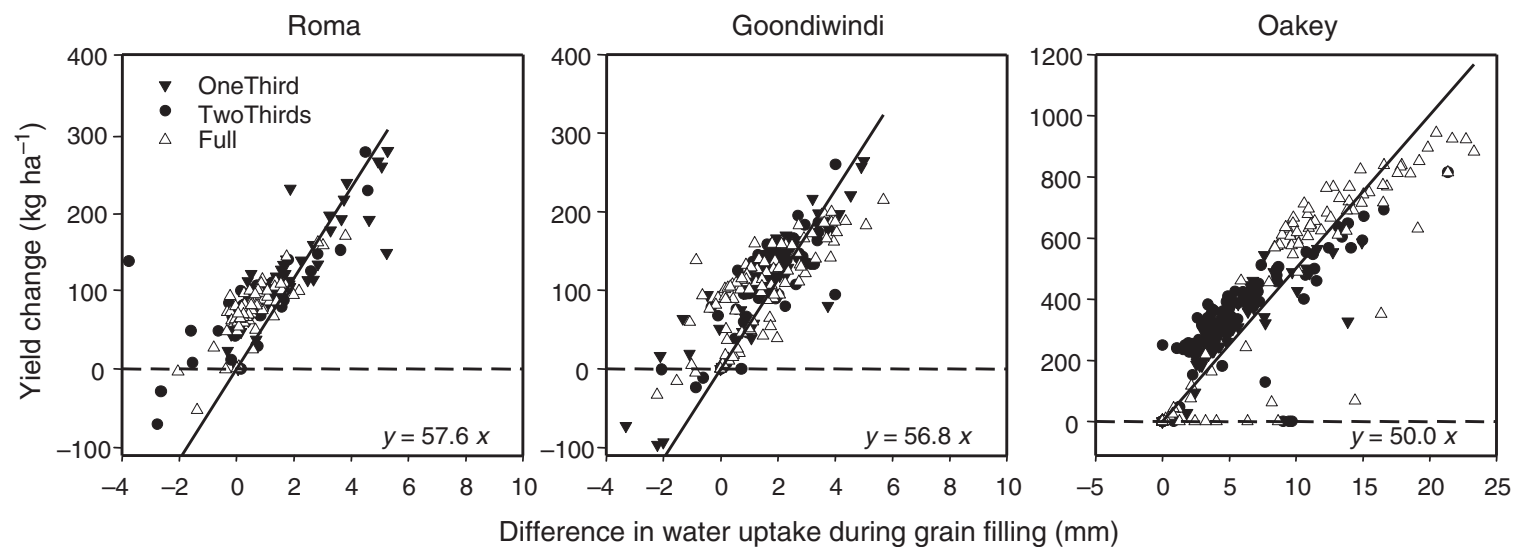

Fig. 10. Yield difference between the standard wheat cultivar Hartog and the RM genotype plotted against difference in water uptake during the grain filling phase (for legends see Fig. 9).

yielded less than Hartog in only a very few simulations, when crops were grown on adequate stored soil moisture and exposed to severe terminal drought. Regression analysis of the data presented in Fig. 10 showed that the water use efficiency during grain filling was $\sim 55 \mathrm{~kg} \mathrm{ha}^{-1}$ grain per $\mathrm{mm}$ of extra water extracted.

\section{Discussion}

\section{Root observation chambers}

The primary objective of our study was to characterise the difference in the patterns of root growth and water extraction in wheat genotypes differing in tolerance to water limitation. We used root observation chambers and a digital imaging technique to compare root development of a standard wheat cultivar (Hartog) with a drought-tolerant line (SeriM82). This system allowed for continuous nondestructive measurements of root length visible at the soilPerspex interface. The experimental method is well suited to investigation of the genotypic differences in potential root growth under continuously drying soil conditions in the absence of any physical or chemical constraints. Patterns of root growth and water extraction observed in this system will not necessarily correspond precisely to those observed for plants competing for resources under actual field conditions. However, they do allow observation of genetic differences that are difficult to detect under field conditions.

Compared with smaller rhizoboxes reported in previous root studies, the root chamber design used here provides several advantages. The large volume of soil in the chambers allowed plant growth and development until maturity even when plants were grown entirely on stored soil water. This is critically important for the identification of desirable root traits that are expressed late in the season in response to terminal drought stress. The wheat genotypes tested in our root chambers produced on average $55 \mathrm{~g}$ grain per plant, which is substantially higher than $4.0-12.5$ g grain plant $^{-1}$ reported for wheat plants grown in smaller glass-faced boxes (Hurd 1968). The large dimensions of the chambers 
also permitted observation of genetic variation in spatial configuration of the whole root system, i.e. root architecture, which is not possible to quantify in narrower root boxes used previously (Hurd 1968; O'Brien 1979). Further, in contrast to other root studies using either small root chambers positioned at a $45^{\circ}$ angle (Kuchenbuch and Ingram 2002; Price et al. 2002) or larger root boxes with a sloping glass face (Hurd 1968; O’Brien 1979), the root chambers in this study were designed with vertical Perspex sides, so that roots did not grow preferentially towards the transparent surface, as demonstrated in Fig. 5. Therefore, the root length visible at the Perspex panel in our system can be considered as a close representation of the actual root-length density in the soil.

\section{Genotypic variation in root characteristics and water uptake}

In our root chamber study, root architecture differed markedly among the wheat and barley genotypes with the drought-tolerant wheat line SeriM82 exhibiting the most compact root architecture. The maximum lateral root extension measured from the stem base was $\sim 45,60$, and $75 \mathrm{~cm}$ for SeriM82, Hartog, and barley cv. Mackay, respectively (Fig. 2). Literature on the genetic variation in root architecture, in particular the potential lateral root spread in cereals is very limited. Weaver (1926) reported that roots of field-grown spring wheat and barley occupied a volume of soil extending $\sim 30 \mathrm{~cm}$ on all sides of the plant. The relatively greater lateral root spread in our study might be a genetic effect as well as a consequence of the limited thickness of the soil in the chambers $(10 \mathrm{~cm})$, which might have caused a more horizontal root growth compared with the real three-dimensional field situation. However, the chamber thickness was greater than plant-to-plant spacing in most field situations and the shape of the chamber presents a soil volume similar to that available to an individual plant in a row crop configuration. The root chamber design used here appears to be suitable for comparative studies of genotypic variation in lateral root distribution. The more extensive lateral root growth of barley observed in our root chambers agrees well with the field observations reporting greater rootlength density and root dry weight of barley in the top $30 \mathrm{~cm}$ soil compared with wheat genotypes (Gregory et al. 1992; López-Castañeda and Richards 1994a). The visible depth of rooting did not differ between the wheat and barley genotypes in our study. Given that the roots of cereal crops can reach a depth of over $200 \mathrm{~cm}$ in favourable soil environments (Hoad et al. 2001), the lack of genotypic variation in maximum depth of rooting in our study was most likely due to the limited depth of soil in the root chambers. This limitation may also have led to a lack of expression of increased yield in SeriM82. SeriM82 produced significantly more roots and extracted more water at depth (Figs 4,6). Such additional root growth requires allocation of more assimilate to roots during grain filling. We hypothesise that the net moisture gain from this additional investment in the root system by SeriM82 was not sufficient to support extra yield in this system.

The differences in root architecture between the wheat and barley genotypes may be attributed to genotypic variation in the angle of seminal roots. Nakamoto and Oyanagi (1994) suggested that deeply rooted wheat genotypes exhibit a narrower angle of seminal roots, while genotypes with a shallower root system tend to grow their seminal roots more horizontally. Similarly, Liao et al. (2001) demonstrated that root architecture in common bean (Phaseolus vulgaris L.) is closely related to the angle of basal roots. Root architecture is known to play an important role in soil resource acquisition and hence plant productivity and adaptation to suboptimal soil conditions (Lynch 1995; Fitter 2002; Ho et al. 2005). In wheat, Oyanagi (1994) reported that cultivars adapted to drier environments displayed a smaller seminal root angle and consequently a deeper root system, whereas genotypes developed for more favourable, wetter environments showed a more horizontal seminal root growth and superficial root systems. Similarly, Bengough et al. (2004) observed a relatively narrower angular spread of seminal roots in wild barley when compared with modern cultivars. The authors hypothesised that narrower angular spread and, hence, a deeper root system was an advantage for plant species such as wild barley that had evolved in water-limiting conditions where obtaining water from depth was important for survival. Our results on genotypic differences in root architecture are consistent with these findings and suggest that the superior performance of SeriM82 under drought conditions is most likely related to its relatively compact and deep root system.

Analysis of genotypic variation in the spatial patterns of root length distribution showed that SeriM82 was capable of producing greater length of roots in the deeper soil layers (Fig. 4). Development of an extensive root network at depth in response to soil drying in surface layers has been reported as an important drought-adaptive root trait in many crop species (O'Toole and Bland 1987) including wheat (Hurd 1968; Asseng et al. 1998b; Manske and Vlek 2002; Xue et al. 2003). Further, visual comparison of root images from the top $70 \mathrm{~cm}$ soil layers indicated that the roots of SeriM82 were distributed more evenly in a given volume of soil (Fig. 5). While the two-dimensional root images did not allow us to quantify the genetic variation in branching pattern, water extraction data from the top soil layers (Fig. 6), where the root lengths were similar in both wheat genotypes, suggest that greater water depletion by SeriM82 was likely due to a more uniform root branching pattern and, hence, enhanced 'occupancy' of the soil by roots. Similar to our results, Angadi and Entz (2002) attributed the relatively greater soil moisture depletion by a standard-height sunflower cultivar to more uniform root distribution, as the root-length densities did not differ between the cultivars compared. While 
non-uniform root distribution as the result of preferential root growth within networks of continuous soil macropores (i.e. previously established root channels, worm holes, and other biopores), is known to reduce the efficiency of water absorption (Passioura 1991; Smucker and Aiken 1992), literature on genetic variation in geometric root distribution and its implication for soil water acquisition is limited, and to our knowledge such variation has not previously been reported in wheat. For sorghum, Masi and Maranville (1998) quantified genotypic variation in root branching structure using fractal analysis and suggested that African-derived materials adapted to suboptimal environments had a greater degree of branching than the genotypes originating in more favourable environments.

\section{Root architecture and adaptation to water limitation}

The genotypic variation in root architecture presented here may have significant functional implications for the timing and amount of soil water uptake. We hypothesise that root architectural differences between the drought-tolerant wheat (SeriM82) and Barley (Mackay) genotypes may result in two contrasting adaptations to cope with water limitation. The compact, uniform and deep root architecture of SeriM82 appears to reduce water use early in the season and increase access to water from the deeper soil layers during the reproductive phase. In field studies, SeriM82 exhibits a less vigorous early shoot growth and is able to retain more green leaf area under post-anthesis drought which leads to extended duration of grain filling and greater yield (Christopher et al. 2005). These field observations are supportive of our hypothesis, as the stay-green trait in SeriM82 may in part be attributed to the ability of its root system to extract more water from the subsoil late in the season. The droughttolerant barley variety Mackay, in contrast, appears to develop a large and shallow root system with greater potential for water extraction from the top soil layers during the vegetative growth phase. This drought-adaptive strategy therefore relies on optimising the timing of soil water extraction rather than increasing the total amount of water use. Experimental results from comparative studies on wheat and barley crops grown in winter-rainfall environments (Gregory et al. 1992; López-Castañeda and Richards 1994b) agree well with our hypothesis. In those studies, the higher yield of barley was attributed to (i) greater water use and above-ground biomass production early in the season when vapour pressure deficit was low, (ii) reduced evaporative loss of water from the soil surface, (iii) greater water-use efficiency for aboveground biomass production, i.e. the ratio of biomass to total evapotranspiration, rather than increased total water use, and (iv) earlier commencement of flowering. Therefore, we conclude that the adaptations of SeriM82 would be more suitable for environments where crops rely largely on stored water in subsoil, while adaptations of Mackay would be beneficial in winter-rainfall environments where crop growth and yield formation is mainly determined by in-season rainfall.

\section{Selecting for desirable root traits}

The root characters identified in this study might prove useful as secondary selection criteria in breeding programs, providing these physiological traits are highly heritable and relatively simple and inexpensive to screen, which is a key requirement for breeding programs (Richards 2006). Desirable root traits that are usually expressed at later stages of crop development, such as greater distribution of roots at depth and uniform root branching pattern, appear to be less suitable for large-scale, cost-effective screening programs, unless they can be reliably linked with surrogate measures such as canopy temperature (Fischer et al. 1998; Reynolds et al. 1999). In addition, root characteristics exhibit a high degree of phenotypic plasticity in response to temporal and spatial variation in rooting environment (Poorter and Nagel 2000; Fitter 2002), which complicates the identification of genotypic variation in drought-adaptive root traits (Price et al. 2002). Therefore, for root traits to be useful as secondary selection criteria in wheat improvement programs, they should ideally be expressed at an early stage and determine the growth and functioning of the root system later in the season. The angle of seminal roots appears to be such a trait, as it seems to strongly influence the root architecture and thus the timing and amount of water uptake. Rapid and costeffective screening for this trait can be undertaken using the small gel-filled root chambers described by Bengough et al. (2004). However, further research is required to identify the extent of genetic variability in angular spread of seminal roots in wheat germplasm and to quantify the impact of this trait on the temporal and spatial patterns of water uptake and grain yield formation.

\section{Simulation analysis of root traits modifications}

The purpose of the simulation analysis was to assess quantitatively the response of wheat yields to genetic modification of root system characteristics in a wide range of rainfed environments. Linking the cropping system model APSIM to long-term weather data from three locations contrasting in soil water-holding capacity, provided the opportunity to evaluate the combined effects of improved root branching structure (occupancy) and increased rootlength distribution at depth (effectiveness) on wheat grain yield under a wide range of water supply conditions. The values of the parameters $k l$ and LL15 used in the simulations (Fig. 7) resulted in increased access of the RM genotype to soil-available water below $50 \mathrm{~cm}$ depth. Given the root elongation rate of $30 \mathrm{~mm} \mathrm{day}^{-1}$ in APSIM-Wheat, the RM genotype was able to extract more water from around four weeks after emergence until crop maturity. Simulation results indicated that wheat yields were generally increased by the changes in water extraction, in particular in low- 
yielding seasons when the initial soil water content was at one-third of PAWC. The magnitude of simulated relative yield benefit corresponds with the experimental findings of Peake et al. (1996) with SeriM82 grown in multi-environment trials (METs) in north-eastern Australia. Further, our results are supportive of previous research suggesting that major increases in yield will require root systems that can access more soil water under water-deficit conditions (Passioura 1983; Ludlow and Muchow 1990). Only in a very few seasons at Roma and Goondiwindi where the simulated crops were grown on adequate stored soil moisture and experienced severe terminal drought stress, changes in the root traits resulted in a yield penalty because plants used more water during the vegetative phase and hence ran out of water in the grain-filling stage.

A key finding from the simulation analysis was that each extra $1 \mathrm{~mm}$ of water extracted by the root system during grain filling leads on average to an additional $55 \mathrm{~kg} \mathrm{ha}^{-1}$ of grain yield. Given that the average wheat yield in rainfed environments in Australia is $\sim 2000 \mathrm{~kg} \mathrm{ha}^{-1}$, capturing only $10 \mathrm{~mm}$ more water during grain filling translates to an increased yield of $\sim 500 \mathrm{~kg} \mathrm{ha}^{-1}$ - a $25 \%$ increase in wheat productivity. The greater efficiency of water captured late in the season has also been documented in fieldgrown wheat crops. Angus and van Herwaarden (2001) estimated that the efficiency of water extracted after anthesis is $33 \mathrm{~kg} \mathrm{ha}^{-1} \mathrm{~mm}^{-1}$ for grain yield, compared with only $6-7 \mathrm{~kg} \mathrm{ha}^{-1} \mathrm{~mm}^{-1}$ for water used pre-anthesis. Similar to our simulation results, J Kirkegaard (pers. comm.) measured an efficiency of $67 \mathrm{~kg}$ wheat grain $\mathrm{ha}^{-1}$ for each extra millimetre of water extracted from subsoil late in the season. The greater values for water productivity during grain filling stem from the combination of improved retranslocation of pre-anthesis carbohydrates stored in the vegetative tissue and increased efficiency of water use for grain production, as the additional growth is directed almost entirely to grain.

It is important to note that the overall advantage of the root traits presented here must be interpreted in the context of the type of environment in which the wheat simulations were conducted and the approaches and assumptions used in modelling root growth and water uptake in APSIMWheat. The environments in our simulation analysis represent wheat-growing areas where stored soil moisture is critical for successful cropping and in-season rainfall is often low. Our simulation results suggest that wheat yields in these environments can generally be improved by genetic improvement in root traits that contribute to increased water extraction during both pre- and post-anthesis phases. However, in environments where wheat crops rely largely on in-season rainfall, increased water consumption during the vegetative growth is likely to reduce wheat yield because of reduced availability of water for grain filling (Dreccer et al. 2002). This is particularly important in Australia, where a significant amount of wheat is grown in both types of environments. Our simulation analysis compared outcomes between plant types for the wheat cropping season only, assuming similar conditions at sowing for each. The actual antecedent moisture conditions realised at sowing will depend on the crop rotation employed, which has a wide range of possibilities. The slightly greater water use of the RM genotype may influence conditions in subsequent years. It is likely that such effects will be minor when the spectrum of rotational systems possible and frequency of profile recharge is considered. While APSIM is capable of simulating rotational systems and consequences of these effects, we did not extend the analysis to do so in this study.

In a manner similar to many other crop growth models, the approach to modelling root growth and water uptake used in APSIM-Wheat focuses on simulating the water uptake function of roots rather than root growth itself (Wang and Smith 2004). While this framework allowed modification of the $k l$ and LL15 parameters to simulate the impact of uniform root distribution with depth on water uptake and yield formation in the RM genotype, it does not account for the carbohydrate cost of increased root growth at depth. Therefore, the simulated yield advantage of the RM genotype over the standard wheat $\mathrm{cv}$. Hartog presented here is only valid on the assumption that the RM genotype is capable of allocating more root growth at depth by reducing the root-length densities in the surface soil layers. This pattern of vertical distribution of roots has been shown to give a greater economic return on carbon investment in roots for water capture (King et al. 2003), as root length densities in surface layers appear to be far higher than are needed for full exploitation of soil water (Passioura 1983; Hamblin et al. 1990).

\section{Conclusion}

The results of this study indicate that genotypic variation in root system characteristics has significant functional implications for water uptake and crop productivity in drought-prone environments. Root architecture and vertical pattern of root distribution appear to be the key water characteristics for improved adaptation in such environments. Genetic differences in root architecture between the droughttolerant wheat (SeriM82) and barley (Mackay) genotypes may be associated with two contrasting adaptation strategies: The compact, uniform and deep root architecture of SeriM82 appears to reduce water use early in the season and increase access to water from the deeper soil layers during the grainfilling phase. In contrast, the adaptation of barley cv. Mackay is based on developing a large and shallow root system with greater potential for water extraction early in the season in order to optimise the timing of soil water extraction rather than increasing the total amount of water use. Therefore, root architecture appears to represent a key target trait for genetic improvement of root systems to increase wheat productivity under water limitation. 
Simulation analysis of modified root traits proved to be a valuable approach for design and evaluation of improved wheat genotypes in a much larger sample of environments than is possible experimentally, for instance in traditional multi-environment breeding trials. Simulation results suggest that selection for drought-tolerant wheat genotypes should focus on improving root system characteristics to allow for more water uptake during the grain filling period, as the extra water can be converted to grain yield with an efficiency of $55 \mathrm{~kg} \mathrm{ha}^{-1} \mathrm{~mm}^{-1}$.

\section{Acknowledgments}

We thank Mr Ian Broad for his excellent assistance in conducting the root chamber experiment. Part of this research was funded by the Grains Research and Development Corporation (GRDC) of Australia. The authors gratefully acknowledge the constructive and critical comments of three anonymous reviewers.

\section{References}

Angadi SV, Entz MH (2002) Root system and water use patterns of different height sunflower cultivars. Agronomy Journal 94, 136-145.

Angus JF, van Herwaarden AF (2001) Increasing water use and water use efficiency in dryland wheat. Agronomy Journal 93, 290-298.

Araus JL, Slafer GA, Reynolds MP, Royo C (2002) Plant breeding and drought in $\mathrm{C}_{3}$ cereals: what should we breed for? Annals of Botany 89, 925-940. doi: 10.1093/aob/mcf049

Asseng S, Keating BA, Fillery IRP, Gregory PJ, Bowden JW, Turner NC, Palta JA, Abrecht DG (1998a) Performance of the APSIM-wheat model in Western Australia. Field Crops Research 57, 163-179. doi: 10.1016/S0378-4290(97)00117-2

Asseng S, Ritchie JT, Smucker AJM, Robertson MJ (1998b) Root growth and water uptake during water deficit and recovering in wheat. Plant and Soil 201, 265-273. doi: 10.1023/ A: 1004317523264

Bengough AG, Gordon DC, Al-Menaie H, Ellis RP, Allan D, Keith R, Thomas WTB, Forster BP (2004) Gel observation chamber for rapid screening of root traits in cereal seedlings. Plant and Soil 262, 63-70. doi: 10.1023/B:PLSO.0000037029.82618.27

Broad I, Hammer GL (2004) Soil exploration by sorghum root systems in wide row cropping systems. In 'New directions for a diverse planet', Proceedings of the 4th international crop science congress, www.cropscience.org.au/icsc2004/

Chapman SC, Cooper M, Hammer GL (2002) Using crop simulation to generate genotype by environment interaction effects for sorghum in water-limited environments. Australian Journal of Agricultural Research 53, 379-389. doi: 10.1071/AR01070

Christopher JT, Manschadi AM, Borrell AK, Hammer GL (2005) A staygreen wheat with high yield under rain fed conditions in sub tropical Australia. In 'Proceedings of the 2nd international conference on integrated approaches to sustain and improve plant production under drought stress - InterDrought II, Rome, Italy, September 24-28, 2005'. P 5.15.

Cooper M, Jensen NM, Carroll BJ, Godwin ID, Podlich DW (1999) QTL mapping activities and marker assisted selection for yield in the Germplasm Enhancement Program of the Australian Northern Wheat Improvement Program. In 'Molecular approaches for the genetic improvement of cereals for stable production in waterlimited environments'. (Eds J-M Ribaut, D Poland) pp. 120-127. (CIMMYT: El Batan)
Cooper M, Woodruff DR, Phillips IG, Basford KE, Gilmour AR (2001) Genotype-by-management interactions for grain yield and grain protein concentration of wheat. Field Crops Research 69, 47-67. doi: 10.1016/S0378-4290(00)00131-3

Dardanelli JL, Bachmeier OA, Sereno R, Gil R (1997) Rooting depth and soil water extraction patterns of different crops in a silty loam Haplustoll. Field Crops Research 54, 29-38. doi: 10.1016/S03784290(97)00017-8

Dreccer MF, Rodriguez D, Ogbonnaya F (2002) Tailoring wheat for marginal environments: a crop modelling study. In 'Proceedings of the 12th Australasian plant breeding conference. September 2002, Perth, Australia'. (Ed. JA McComb) pp. 457-462. (The Australiasian Plant Breeding Association, Inc.: Perth)

Fischer KS (1996) Research approaches for variable rainfed systems thinking globally, acting locally. In 'Plant adaptation and crop improvement'. (Eds M Cooper, GL Hammer) pp. 25-35. (CAB International, ICRISAT, IRRI: Wallingford)

Fischer KS, Edmeades GO, Johnson EC (1989) Selection for the improvement of maize yield under moisture-deficits. Field Crops Research 22, 227-243. doi: 10.1016/0378-4290(89)90094-4

Fischer RA, Rees D, Sayre KD, Lu Z-M, Condon AG, Saavedra AL (1998) Wheat yield progress associated with higher stomatal conductance and photosynthetic rate, and cooler canopies. Crop Science 38, 1467-1475.

Fitter A (2002) Characteristics and functions of root systems. In 'Plant roots: the hidden half'. (Eds Y Waisel, A Eshel, U Kafkafi) pp. 249-259. (Marcel Dekker Inc: New York)

Fukai S, Pantuwan G, Jongdee B, Cooper M (1999) Screening for drought resistance in rainfed lowland rice. Field Crops Research 64, 61-74. doi: 10.1016/S0378-4290(99)00051-9

Gregory PJ, Tennant D, Belford RK (1992) Root and shoot growth, and water and light use efficiency of barley and wheat crops grown on a shallow duplex soil in a Mediterranean-type environment. Australian Journal of Agricultural Research 43, 555-573. doi: 10.1071/ AR9920555

Hamblin A, Tennant D, Perry MW (1990) The cost of stress: dry matter partitioning changes with seasonal supply of water and nitrogen to dryland wheat. Plant and Soil 122, 47-58.

Hammer GL, Butler DG, Muchow RC, Meinke H (1996) Integrating physiological understanding and plant breeding via crop modelling and optimization. In 'Plant adaptation and crop improvement'. (Eds M Cooper, GL Hammer) pp. 419-441. (CAB International, ICRISAT, IRRI: Wallingford)

Hammer GL, Kropff MJ, Sinclair TR, Porter JR (2002) Future contributions of crop modelling - from heuristics and supporting decision making to understanding genetic regulation and aiding crop improvement. European Journal of Agronomy 18, 15-31. doi: 10.1016/S1161-0301(02)00093-X

Hammer G, Chapman S, van Oosterom E, Podlich D (2005) Trait physiology and crop modelling as a framework to link phenotypic complexity to underlying genetic systems. Australian Journal of Agricultural Research 56, 947-960. doi: 10.1071/AR05157

Ho MD, Rosas JC, Brown KM, Lynch JP (2005) Root architectural tradeoffs for water and phosphorus acquisition. Functional Plant Biology 32, 737-748. doi: 10.1071/FP05043

Hoad SP, Russell G, Lucas ME, Bingham IJ (2001) The management of wheat, barley, and oat root systems. In 'Advances in agronomy'. pp. 193-246. (Academic Press: San Diego)

Horridge M, Madden J, Wittwer G (2005) The impact of the 2002-2003 drought on Australia. Journal of Policy Modeling 27, 285-308. doi: 10.1016/j.jpolmod.2005.01.008

Hurd EA (1968) Growth of roots of seven varieties of spring wheat at high and low moisture levels. Agronomy Journal 60, 201-205.

Hurd EA (1974) Phenotype and drought tolerance in wheat. Agricultural Meteorology 14, 39-55. doi: 10.1016/0002-1571(74)90009-0 
Jackson P, Robertson M, Cooper M, Hammer G (1996) The role of physiological understanding in plant breeding; from a breeding perspective. Field Crops Research 49, 11-37. doi: 10.1016/S03784290(96)01012-X

Keating BA, Meinke H, Probert ME, Huth NI, Hills IG (2001) NWheat: documentation and performance of a wheat module for APSIM. CSIRO Tropical Agriculture Technical Memorandum No. 9, Australia.

Keating BA, Carberry PS, Hammer GL, Probert ME, Robertson MJ, et al. (2003) An overview of APSIM, a model designed for farming systems simulation. European Journal of Agronomy 18, 267-288. doi: 10.1016/S1161-0301(02)00108-9

King J, Gay A, Sylvester-Bradley R, Bingham I, Foulkes J, Gregory P, Robinson D (2003) Modelling cereal root systems for water and nitrogen capture: towards an economic optimum. Annals of Botany 91, 383-390. doi: 10.1093/aob/mcg033

Kuchenbuch RO, Ingram KT (2002) Image analysis for non-destructive and non-invasive quantification of root growth and soil water content in rhizotrons. Journal of Plant Nutrition and Soil Science 165, 573-581. doi: 10.1002/1522-2624(200210)165:5<573::AIDJPLN573>3.0.CO;2-W

Liao H, Rubio G, XiaoLong Y, AiQin C, Brown KM, Lynch JP (2001) Effect of phosphorus availability on basal root shallowness in common bean. Plant and Soil 232, 69-79. doi: 10.1023/A: 1010381919003

Liao M, Ian RP, Fillery IRP, Palta JA (2004) Early vigorous growth is a major factor influencing nitrogen uptake in wheat. Functional Plant Biology 31, 121-129. doi: 10.1071/FP03060

López-Castañeda C, Richards RA (1994a) Variation in temperate cereals in rainfed environments. I. Grain yield, biomass and agronomic characteristics. Field Crops Research 37, 51-62. doi: 10.1016/0378-4290(94)90081-7

López-Castañeda C, Richards RA (1994b) Variation in temperate cereals in rainfed environments. III. Water use and water-use efficiency. Field Crops Research 39, 85-98. doi: 10.1016/03784290(94)90011-6

Ludlow MM, Muchow RC (1990) A critical evaluation of traits for improving crop yields in water-limited environments. Advances in Agronomy 43, 107-153.

Lynch J (1995) Root architecture and plant productivity. Plant Physiology 109, 7-13.

Manske GGB, Vlek PLG (2002) Root architecture - wheat as a model plant. In 'Plant roots: the hidden half'. (Eds Y Waisel, A Eshel, U Kafkafi) pp. 249-259. (Marcel Dekker Inc.: New York)

Masi CEA, Maranville JW (1998) Evaluation of sorghum root branching using fractals. Journal of Agricultural Science 131, 259-265. doi: $10.1017 / \mathrm{S} 0021859698005826$

Meinke H, Hammer GL, Want P (1993) Potential soil water extraction by sunflower on a range of soils. Field Crops Research 32, 59-81. doi: 10.1016/0378-4290(93)90021-E

Meinke H, Hammer GL, van Keulen H, Rabbinge R, Keating BA (1997) Improving wheat simulation capabilities in Australia from a cropping systems perspective. I. Water and nitrogen effects on spring wheat in a semi-arid environment. European Journal of Agronomy 7, 75-88. doi: 10.1016/S1161-0301 (97)00032-4

Meinke H, Hammer GL, van Keulen H, Rabbinge R (1998) Improving wheat simulation capabilities in Australia from a cropping systems perspective. III. The integrated wheat model (I_WHEAT). European Journal of Agronomy 8, 101-116. doi: 10.1016/S11610301(97)00015-4

Monteith JL (1986) How do crops manipulate water supply and demand? Philosophical Transactions of the Royal Society of London. Series A 316, 245-258.
Muchow RC, Carberry PS (1993) Designing improved plant types for the semiarid tropics: agronomists' viewpoints. In 'Systems approaches for agricultural development'. (Eds FWT Penning de Vries, PS Teng, K Metselaar) pp. 37-61. (Kluwer Academic Publishers: Dordrecht)

Nakamoto T, Oyanagi A (1994) The direction of growth of seminal roots of Triticum aestivum $\mathrm{L}$. and experimental modification thereof. Annals of Botany 73, 363-367. doi: 10.1006/anbo.1994.1045

O'Brien L (1979) Genetic variability of root growth in wheat (Triticum aestivum L.). Australian Journal of Agricultural Research 30, 587-595. doi: 10.1071/AR9790587

O'Toole JC, Bland WL (1987) Genotypic variation in crop plant root systems. Advances in Agronomy 41, 91-145.

Oyanagi A (1994) Gravitropic response growth angle and vertical distribution of roots of wheat (Triticum aestivum L.). Plant and Soil 165, 323-326. doi: 10.1007/BF00008076

Passioura JB (1972) The effect of root geometry on the yield of wheat growing on stored water. Australian Journal of Agricultural Research 23, 745-752. doi: 10.1071/AR9720745

Passioura JB (1983) Roots and drought resistance. Agricultural Water Management 7, 265-280. doi: 10.1016/0378-3774(83)90089-6

Passioura JB (1991) Soil structure and plant growth. Australian Journal of Soil Research 29, 717-728. doi: 10.1071/SR9910717

Passioura JB (2006) Increasing crop productivity when water is scarce - from breeding to field management. Agricultural Water Management 80, 176-196. doi: 10.1016/j.agwat.2005.07.012

Peake AS, Cooper M, Fabrizius MA (1996) The relationship between the $1 \mathrm{BL} / 1 \mathrm{RS}$ translocation and grain yield in three wheat populations in Queensland environments. In 'Proceedings of the 8th assembly of the Wheat Breeding Society of Australia'. Canberra ACT, Australia. (Eds R Richards, C Wrigley, H Rawson, G Rebetzke, J Davidson, R Brettell) pp. 20-23.

Poorter H, Nagel O (2000) The role of biomass allocation in the growth response of plants to different levels of light, $\mathrm{CO}_{2}$, nutrients and water: a quantitative review. Australian Journal of Plant Physiology 27, 595-607.

Price AH, Steele KA, Gorham J, Bridges JM, Moore BJ, Evans JL, Richardson P, Jones RGW (2002) Upland rice grown in soil-filled chambers and exposed to contrasting water-deficit regimes: I. Root distribution, water use and plant water status. Field Crops Research 76, 11-24. doi: 10.1016/S0378-4290(02)00012-6

Rebetzke GJ, Richards RA (1999) Genetic improvement of early vigour in wheat. Australian Journal of Agricultural Research 50, 291-302. doi: 10.1071/A98125

Reynolds MP, Rajaram S, Sayre KD (1999) Physiological and genetic changes of irrigated wheat in the post-green revolution period and approaches for meeting projected global demand. Crop Science 39, 1611-1621.

Reynolds MP, Delgado BMI, Gutierrez-Rodriguez M, LarqueSaavedra A (2000) Photosynthesis of wheat in a warm, irrigated environment I: genetic diversity and crop productivity. Field Crops Research 66, 37-50. doi: 10.1016/S0378-4290(99)00077-5

Richards RA (2006) Physiological traits used in the breeding of new cultivars for water-scarce environments. Agricultural Water Management 80, 197-211. doi: 10.1016/j.agwat.2005.07.013

Richards RA, Passioura JB (1989) A breeding program to reduce the diameter of the major xylem vessel in the seminal roots of wheat and its effect on grain yield in rain-fed environments. Australian Journal of Agricultural Research 40, 943-950. doi: 10.1071/ AR9890943

Richards RA, Rebetzke GJ, Condon AG, van Herwaarden AF (2002) Breeding opportunities for increasing the efficiency of water use and crop yield in temperate cereals. Crop Science 42, $111-121$. 
Robertson MJ, Fukai S, Ludlow MM, Hammer GL (1993) Water extraction by grain sorghum in a sub-humid environment. I. Analysis of the water extraction pattern. Field Crops Research 33, 81-97. doi: 10.1016/0378-4290(93)90095-5

Robertson MJ, Carberry PS, Huth NI, Turpin JE, Probert ME, Poulton PL, Bell M, Wright GC, Yeates SJ, Brinsmead RB (2002) Simulation of growth and development of diverse legume species in APSIM. Australian Journal of Agricultural Research 53, 429-446. doi: 10.1071/AR01106

SAS Institute Inc. (1991) 'SAS system for linear models.' (SAS Institute Inc.: Cary)

Shorter R, Lawn RJ, Hammer GL (1991) Improving genotypic adaptation in crops - a role for breeders, physiologists and modellers. Experimental Agriculture 27, 155-175.

Siddique KHM, Belford RK, Tennant D (1990) Root: shoot ratios of old and modern, tall and semi-dwarf wheats in a mediterranean environment. Plant and Soil 121, 89-98. doi: 10.1007/BF00013101

Sinclair TR, Muchow RC (2001) System analysis of plant traits to increase grain yield on limited water supplies. Agronomy Journal 93, 263-270.

Sinclair TR, Hammer GL, van Oosterom EJ (2005) Potential yield and water-use efficiency benefits in sorghum from limited maximum transpiration rate. Functional Plant Biology 32, 945-952. doi: 10.1071/FP05047
Smucker AJM, Aiken RM (1992) Dynamic root responses to water deficits. Soil Science 154, 281-289.

Wang E, Smith CJ (2004) Modelling the growth and water uptake function of plant root systems: a review. Australian Journal of Agricultural Research 55, 501-523. doi: 10.1071/AR03201

Wang E, Robertson MJ, Hammer GL, Carberry PS, Holzworth D, Meinke H, Chapman SC, Hargreaves JNG, Huth NI, McLean G (2002) Development of a generic crop model template in the cropping system model APSIM. European Journal of Agronomy 18, 121-140. doi: 10.1016/S1161-0301(02)00100-4

Wang E, van Oosterom EJ, Meinke H, Asseng S, Robertson MJ, Huth NI, Keating BA, Probert ME (2003) The new APSIM-Wheat model - performance and future improvements. In 'Solutions for a better environment. Proceedings of the 11th Australian agronomy conference, Geelong, Victoria, 2003'. (Australian Society of Agronomy)

Weaver JE (1926) 'Root development of field crops.' (McGraw-Hill Book Company, Inc.: New York)

Xue Q, Zhu Z, Musick JT, Stewart BA, Dusek DA (2003) Root growth and water uptake in winter wheat under deficit irrigation. Plant and Soil 257, 151-161. doi: 10.1023/A:1026230527597

Manuscript received 14 March 2006, accepted 14 June 2006 